\title{
Sero-Prevalence of Brucellosis in Occupationally High-Risk Groups in Three Different Districts of Khyber Pakhtunkhwa, Pakistan
}

\author{
Aman Ullah ${ }^{1}$, Hamaad Ali ${ }^{2}$, Falak Niaz ${ }^{3}$, Muhammad Umair Khan ${ }^{2}$, Muhammad Asif Zeb ${ }^{1}$, Noor \\ Rehman $^{4}$ \\ ${ }^{1}$ Lecturer, Institute of Paramedical Sciences, Khyber Medical University, Peshawar \\ ${ }^{2}$ Student, Medical Lab Technology, National Institute of Health and Management Sciences, Peshawar \\ ${ }^{3}$ Lecturer, Medical Lab Technology, National Institute of Health and Management Sciences, Peshawar \\ ${ }^{4}$ Lab Technologist, Institute of Basic Medical Sciences, Khyber Medical University, Peshawar
}

ABSTRACT

\begin{abstract}
Objectives: Brucellosis is a neglected zoonotic disease in Pakistan, but it causes immense impact on livestock and public health. This study was done to determine the prevalence of Brucellosis in occupationally high-risk groups encompassing butchers, milkers, and cattle caretakers in district Swabi, Mardan, and Peshawar of Khyber Pakhtunkhwa, Pakistan.

Methods: In this descriptive cross-sectional study, 300 blood samples were collected through a non-probability purposive sampling technique from occupationally high-risk groups including butchers, milkers, and cattle caretakers at district Swabi, Mardan, and Peshawar from December 1, 2017, to March 31, 2018. All the blood samples were centrifuged and the serum was separated for further testing. Serum agglutination test was used for the detection of Brucellosis and the reagents used for this method were purchased from Biosciences PTE Ltd, Singapore.

Results: Out of 300 blood samples, 111 samples were positive and the overall prevalence of Brucellosis was $37 \%$ in occupationally high-risk groups. The overall $37 \%$ prevalence of Brucellosis comprised of $70 \%$ of $B$. abortus, $21.6 \%$ of $B$. melitensis, and $8.1 \%$ of both $B$. abortus and B. melitensis simultaneously. The prevalence of Brucellosis in butchers was $27.6 \%$, milkers $13.3 \%$, and cattle caretakers $45.7 \%$ while prevalence in males was $33 \%$ and in females $39.6 \%$. The prevalence of Brucellosis in district Swabi was $45 \%$, Mardan 33.3\%, and Peshawar 30\%. The socio demographic factors including age group, occupation, and locality showed statistically significant results.

Conclusion: The prevalence of Brucellosis is considerably higher in occupationally high-risk groups in district Swabi, Mardan, and Peshawar, Pakistan.

Keywords: Brucellosis, Brucella abortus, Brucella melitensis, Malta fever, Zoonosis

Authors' Contribution:

${ }^{1}$ Conception; Literature research; manuscript design and drafting; ${ }^{2,3}$ Critical analysis and manuscript review; ${ }^{4-6}$ Data analysis; Manuscript Editing.

$\begin{array}{ll}\text { Correspondence: } & \text { Article info: } \\ \text { Aman Ullah } & \text { Received: October 10, } 2020 \\ \text { Email: khurramthalwi@hotmail.com } & \text { Accepted: August 23, } 2021\end{array}$

Accepted: August 23, 2021
\end{abstract}

Cite this article. Ullah Aman, Ali H, Niaz F, Khan MU, Zeb MA, Rehman N. Sero-Prevalence of Brucellosis in Occupationally High-Risk Groups in Three Different Districts of Khyber Pakhtunkhwa, Pakistan. J Islamabad Med Dental Coll. 2021; 10(3): 176-180. Doi: 10.35787/jimdc.v10i3.620

\section{Introduction}

Brucellosis is a zoonotic disease caused by gramnegative bacteria of genus Brucella (B.) and can cause infection both in animals and humans. ${ }^{1}$
According to the Office International des, Epizooties (OIE) Brucellosis is the second leading zoonotic disease in the world. ${ }^{2}$ World Health Organization 
(WHO) reported that annually 500,000 cases of Brucellosis occur across the globe. ${ }^{3}$ The high prevalence of this infection is gaining increasing attention worldwide. It is also a noticeable issue in Pakistan because previously a study reported $37 \%$ prevalence in 2014. ${ }^{4}$ Only four species are responsible for human Brucellosis including $B$. abortus, B. melitensis, B. suis and B. canis, and their common reservoirs include cattle, sheep and goats, pigs, and dogs respectively. ${ }^{5,6}$

In natural hosts, the transmission mostly occurs through milk or genital secretions during mating. ${ }^{7}$ This infection transfers from animals to humans by using raw milk and other dairy products made from milk like cheese, butter, and ice cream, etc. ${ }^{8}$ It can also be transmitted by inhalation of infectious aerosol, ingestion of infected meat, contact with conjunctival mucosa, or bacteria may enter through injured skin by close contact with animal or their products. ${ }^{9}$ Direct contact with infected cattle and other animals is a common route of transmission, for high-risk groups including slaughterhouse workers, farmers, shepherds, and milkers. ${ }^{10}$

The clinical course of Brucellosis includes undulant fever, sweating, anorexia, muscular pain, and weakness. ${ }^{11}$ Consequently, Brucellosis may lead to osteomyelitis, meningoencephalitis, arthritis, and endocarditis. ${ }^{12}$ Duration of the disease maybe a few weeks or months to several years. ${ }^{13}$

In developing countries, Brucellosis is most frequently diagnosed by many serological tests such as the Serum agglutination test (SAT), Complement fixation test (CFT), Rose bengal test (RBPT), and Enzyme-linked immunosorbent assay (ELISA). ${ }^{2}$

In Pakistan, Brucellosis has been neglected, only a few studies have been reported from different areas of the country. There are groups of people in Khyber Pakhtunkhwa who rear cattle therefore, they remain in intimate contact with them for care, milking, and slaughtering the cattle. Hence, they are at higher risk of transmission of zoonotic diseases including Brucellosis. Therefore, epidemiological data about prevalence of this disease is of utmost importance in devising preventive strategies for an effective infection control program.

The current study aims to determine the seroprevalence of Brucellosis in occupationally highrisk groups including butchers, milkers, and cattle caretakers in district Swabi, Mardan, and Peshawar, Khyber Pakhtunkhwa, Pakistan.

\section{Methodology}

This descriptive cross-sectional study was conducted in three districts of Khyber Pakhtunkhwa including Swabi, Mardan, and Peshawar from December 1, 2017, to March 31, 2018. A total of 300 blood samples were collected from all the participants enrolled in the study after meeting the inclusion criteria. A non-probability purposive sampling technique was used. The sample size was calculated using the sample size calculating formula as

Sample size $(n)=Z^{2} \times(p \times q) / e^{2}$

$=1.96^{2} \times 0.27 \times(1-0.27) / 0.05^{2}$

$=302.8$

where,

$\mathrm{n}=$ required sample size

$\mathrm{p}=$ prevalence of Brucellosis in Khyber

Pakhtunkhwa (27\% from the previous study)

$q=1-p$

$\mathrm{e}=$ margin of error, $5 \%$

$\mathrm{Z}=1.96$ at $95 \% \mathrm{Cl}$

The study was approved by the ethical review committee of the National Institute of Health and Management Sciences (NIHMS), Peshawar, and all the participants were explained about the study and informed consent was obtained.

The participants of the study comprised occupationally high-risk groups including 65 butchers, 45 milkers, and 190 cattle caretakers. All the blood samples were collected in a gel tube and transported to NIHMS on the same day. Serum was separated from each blood sample by centrifugation and was screened qualitatively for the detection of antibodies against B. abortus and B. melitensis 
according to the instructions of the manufacturer (Biosciences PTE Ltd, Singapore). ${ }^{14}$ In detail, $40 \mu$ l of both serum and reagent was mixed on a slide and gently agitated for 4 minutes. The slide was observed for agglutination and the result was recorded. The sensitivity and specificity of the reagent used was $98 \%$ and $97 \%$ respectively.

The data obtained were entered into the SPSS version 22.0 for statistical analysis. Descriptive analysis was used for the calculation of percentages and frequencies, while chi square test was applied to determine the statistical significance with age group, occupation, and locality.

\section{Results}

Out of 300 blood samples $37 \%(\mathrm{~N}=111)$ samples were positive for Brucellosis, wherein 70.3\% ( $\mathrm{N}=78)$ samples gave positive results for B. abortus, $21.6 \%$ $(\mathrm{N}=24)$ samples were positive for $B$. melitensis, and 8.1\% ( $\mathrm{N}=09)$ blood samples were found positive for both $B$. abortus and B. melitensis. Prevalence of Brucellosis was higher in females than males, whilst the most affected age group was 21-40 years.
Amongst the occupationally high-risk group, Brucellosis was most prevalent among cattle caretakers and geographically it was found more in district Swabi as presented in Table I.

All the butchers included in the study were males while milkers comprised 11 males and 34 females and cattle caretakers consisted of 42 males and 148 females. Among the total 39 positive male participants, 18 were butchers, 02 were milkers, and 04 were cattle caretakers while in 72 positive female participants 04 were milkers and 69 were cattle caretakers.

The socio demographic factors encompassing age group, occupation, and locality showed statistically significant results. There was a significant difference between various age groups and seroprevalence of Brucellosis with 21-40 years of age most frequently reporting it $(p=<0.01)$. In occupationally high-risk groups, cattle caretakers had statistically significant higher seroprevalence as compared to butchers and milkers with $p$-value $<0.01$. Geographically human brucellosis was more common in district Swabi with p-value $<0.01$.

\begin{tabular}{|l|l|l|l|l|l|l|}
\hline Table I: Prevalence of Brucellosis in occupationally high-risk groups \\
\hline & & Total N & $\begin{array}{l}\text { Positive } \\
\text { N (\%) }\end{array}$ & $\begin{array}{l}\text { B. abortus } \\
\text { N (\%) }\end{array}$ & $\begin{array}{l}\text { B. melitensis } \\
\text { N (\%) }\end{array}$ & $\begin{array}{l}\text { B. abortus \& } \\
\text { B. melitensis } \\
\text { N (\%) }\end{array}$ \\
\hline \multirow{3}{*}{ Gender } & Male & 118 & $39(11)$ & $21(07)$ & $12(04)$ & $06(02)$ \\
\cline { 2 - 7 } & Female & 182 & $72(24)$ & $57(19)$ & $12(04)$ & $03(01)$ \\
\hline \multirow{5}{*}{ Occupation } & Butchers & 65 & $18(06)$ & $12(04)$ & $03(01)$ & $03(01)$ \\
\cline { 2 - 7 } & Milkers & 45 & $06(02)$ & $03(01)$ & $03(01)$ & $00(00)$ \\
\cline { 2 - 7 } & Cattle caretakers & 190 & $87(29)$ & $63(21)$ & $18(06)$ & $06(02)$ \\
\hline \multirow{3}{*}{ Districts } & $<20$ years & 54 & $18(06)$ & $12(04)$ & $06(02)$ & $00(00)$ \\
\cline { 2 - 7 } & $21-40$ & 189 & $75(25)$ & $51(17)$ & $15(05)$ & $09(03)$ \\
\cline { 2 - 7 } & $40-60$ & 57 & $18(06)$ & $15(05)$ & $03(01)$ & $00(00)$ \\
\cline { 2 - 7 } & Swabi & 120 & $54(18)$ & $36(12)$ & $09(03)$ & $09(03)$ \\
\cline { 2 - 7 } & Peshawar & 90 & $30(10)$ & $24(08)$ & $06(02)$ & $00(00)$ \\
\hline
\end{tabular}

\section{Discussion}

Brucellosis is a zoonotic disease and still, a public health problem in developing countries including Pakistan, therefore, the given study endeavored to measure the prevalence of Brucellosis in occupationally high-risk groups. The overall prevalence of Brucellosis in the current study was $37 \%$ while earlier studies reported $12.2 \%$ to $32.9 \%$ prevalence from different districts of the Khyber 
Pakhtunkhwa, Pakistan ${ }^{4}$. Our results show higher prevalence than others as we measured the prevalence in targeted occupationally high-risk groups, mostly with active symptoms of Brucellosis. Our findings documented a higher prevalence in cattle caretakers than other high-risk groups which is in agreement with previously published data, ${ }^{15}$ the possible reason could be their direct contact with infected animals.

The prevalence of $B$. abortus (26\%) is higher than the prevalence of $B$. melitensis (8\%) which can be explained by the reason reported in the literature ${ }^{16}$ that $B$. abortus infects cattle while $B$. melitensis infects sheep and goat, and the participants of the given study were mostly found in close contact with cattle. A study was done by Siddique et al also reported the higher prevalence of $B$. abortus from Pakistan. ${ }^{17}$

Our research also found a higher prevalence in females as compared to the males which validate the finding of another researcher ${ }^{18}$. Usually, females are housewives in this region, and they take care of their cattle at houses therefore, direct contact increases the chance of infection. Hence, it is of utmost importance to educate the females about the symptoms of brucellosis both in animals and humans in order to make early diagnosis and treatment of brucellosis in either case, moreover, route of transmission should also be known to avoid the practices that put them at higher risk of contracting brucellosis. In addition to this, the female participants almost cover two-third of the sample size which could also be a factor of consideration for the increased prevalence of Brucellosis in the females.

In different age strata, the increasing prevalence was found in the 21-40 years group, which is in contradiction with the findings of Shahid et al, ${ }^{4}$ it could be due to the number of participants included in different age groups because it was not standardized in both studies. Moreover, the 21-40 years age group is comprised of the people with the most productive age, and thus, they are more likely to be involved in the laborious activities of cattle farming.

The current study reported higher prevalence in district Swabi as compared to other two districts; it can be explained with a reason that blood sample was collected from participants of district Swabi who reside in extremely remote areas and rear animal folk at their houses, whilst it was not the case in other two districts. Furthermore, the number of participants was higher from district Swabi as compared to the other two districts which further increase the probability of detection of positive cases and subsequently increase prevalence.

All the butchers recruited in the given study were males as due to societal norms and restrictions, females do not adopt this profession in Pakistan. While milkers and cattle caretakers are largely comprised of female participants because females in these districts are usually housewives and they stay inside the houses and perform the duties of milking and taking care of their cattle while males work outside the houses in farms and other areas.

Limitations of the study include a relatively small sample size for three districts and the further confirmation of the positive screening test by any confirmatory test.

\section{Conclusion}

The seroprevalence of brucellosis is significantly higher in occupationally high-risk groups encompassing butchers, milkers, and cattle caretakers in District Swabi, Mardan, and Peshawar

\section{Recommendation}

It is recommended to make a surveillance about the prevalence of brucellosis in high-risk areas of the country, furthermore, the people who rear cattle, sheep, and goats at their homes need proper education and training about the prevention and control of brucellosis.

\section{References}


1. Yousaf R, Khan I, Shehzad W, Hussain R, Ali S, Neubauer H, Wareth G. Seroprevalence and Molecular Detection of Brucellosis in Hospitalized Patients in Lahore Hospitals, Pakistan. Infectious Disease Reports. 2021; 13(1):166-72. Doi: 10.3390/idr13010018

2. Khan $A Q$, Haleem SK, Shafiq $M$, Khan NA, ur Rahman S. Seropositivity of brucellosis in human and livestock in Tribal-Kurram Agency of Pakistan indicates cross circulation. Thai J Vet Med. 2017;47(3):349.

3. O'callaghan D. Human brucellosis: recent advances and future challenges. Infectious Diseases of Poverty. 2020 Dec;9(1):1-2. Doi:10.1186/s40249-020-00715-1

4. Shahid M, Basit A, Khan MA. Prevalence of brucellosis among the hospital patients of Peshawar, Khyber Pakhtunkhwa. J Infect Mol Biol. 2014;2(2):19-21. Doi:10.14737/jimb.2307-5465/2.2.19.21

5. Franc KA, Krecek RC, Häsler BN, Arenas-Gamboa AM. Brucellosis remains a neglected disease in the developing world: a call for interdisciplinary action. BMC public health. 2018; 18(1):1-9. Doi: 10.1186/s12889-017-5016-y

6. González-Espinoza G, Arce-Gorvel V, Mémet S, Gorvel JP. Brucella: Reservoirs and Niches in Animals and Humans. Pathogens. 2021;10(2):186. Doi: 10.3390/pathogens10020186

7. Tuon FF, Gondolfo RB, Cerchiari N. Human-to-human transmission of Brucella-a systematic review. TMIH. 2017; 22(5):539-46. Doi: 10.1111/tmi.12856

8. Rahman AA, Berkvens D, Saegerman C, Fretin D, Muhammad N, Hossain A, Abatih E. Seroprevalence of brucellosis in patients with prolonged fever in Bangladesh. JIDC 2016 Sep 30;10(09):939-46. doi:10.3855/jidc.6844

9. Yohannes M, Mersha T, Degefu H, Tolosa T, Woyesa M. Bovine brucellosis: serological survey in GutoGida district, East Wollega zone, Ethiopia. Global Veterinaria. 2012;8(2):139-43. ISSN 1992-6197
10. Li N, Yu F, Peng F, Zhang X, Jia B. Probable sexual transmission of brucellosis. IDCases. 2020; 21: e00871. DOI: 10.1016/j.idcr. 2020.e00871

11. Roushan MR, Ebrahimpour S, Moulana Z. Different clinical presentations of brucellosis. Jundishapur J Microbiol. 2016; 9(4). Doi: 10.5812/jjm.33765

12. Zheng R, Xie S, Lu X, Sun L, Zhou Y, Zhang Y, Wang K. $A$ systematic review and meta-analysis of epidemiology and clinical manifestations of human brucellosis in China. BioMed research international. 2018 Apr 22;2018. Doi: 10.1155/2018/5712920

13. Al-Sultan II, Ali TI, Ibrahim OE. Incidental occurrence and risk factors of brucellosis in teaching hospital. J Adv Med Res 2011;1(1):1-7. ISSN 2231-8313

14. Hussain, M. A. Seroprevalence of Brucellosis in Sheep and Humans in District Kohat, Pakistan. Adv Anim Vet Sci. $\quad 2014 ; 2(9), \quad 516-523 . \quad$ Doi: 10.14737/journal.aavs/2014/2.9.516.523

15. Omer MK, Assefaw T, Skjerve E, Tekleghiorghis T, Woldehiwet Z. Prevalence of antibodies to Brucella spp. and risk factors related to high-risk occupational groups in Eritrea. Epidemiology \& Infection 2002 Aug;129(1):85-91.

Doi: $10.1017 /$ s0950268802007215

16. Gwida M, Al Dahouk S, Melzer F, Rösler U, Neubauer $\mathrm{H}$, Tomaso $\mathrm{H}$. Brucellosis-regionally emerging zoonotic disease?. Croat Med J. 2010; 51(4):289-95. Doi: 10.3325/cmj.2010.51.289

17. Saddique A, Ali S, Akhter S, Khan I, Neubauer $H$, Melzer $F$, et al. Acute febrile illness caused by Brucella abortus infection in humans in Pakistan. Int J Environ Res public health. 2019;16(21):4071. Doi: 10.3390/ijerph16214071

18. Din AM, Khan SA, Ahmad I, Rind R, Hussain T, Shahid $M$, et al. A study on the seroprevalence of brucellosis in human and goat populations of district Bhimber, Azad Jammu and Kashmir. J Anim Plant Sci 2013; 23:113-8. ISSN: 1018-7081 